\title{
Effect of miR-146a and miR-155 on cardiac xenotransplantation
}

\author{
ZHICHENG ZHAO, FENG QI, TONG LIU and WEIHUA FU \\ Department of General Surgery, Tianjin Medical University General Hospital, Tianjin 300052, P.R. China
}

Received August 25, 2015; Accepted September 9, 2016

DOI: $10.3892 /$ etm.2016.3867

\begin{abstract}
The aim of the present study was to investigate the expression levels of miR-146a and miR-155 in a cardiac xenograft model treated with the immunosuppressant FK506, and to construct lentiviral vectors to further study the roles of miR-146a and miR-155 in cardiac xenotransplantation. Expression levels of miR-146a and miR-155 were examined by quantitative polymerase chain reaction analysis and protein expression of RelA, which is a member of the nuclear factor- $\kappa \mathrm{B}$ family, was examined by western blot analysis. Pre-miR-146a and pre-miR-155 fragments were designed and synthesized according to MiRBase and were cloned into the plasmid pCDH1-MCS1-EF1-copGFP. Recombinant plasmids were identified by enzyme digestion and sequencing. Survival time of cardiac grafts in the FK506 treatment group was significantly increased in comparison with the control group $(\mathrm{P}<0.05)$. In addition, the histopathological grading results were significantly decreased in the treatment group $(\mathrm{P}<0.05)$. A significant decrease in RelA protein expression levels was observed in the treatment group $(\mathrm{P}<0.05)$, along with a significant increase in miR-146a expression levels $(\mathrm{P}<0.05)$ and a significant decrease in miR-155 expression levels $(\mathrm{P}<0.05)$. Digestion and sequencing findings demonstrated that the insertion of miRNA into the plasmid pCDH1-MCS1-EF1-copGFP conformed with the pre-miRNAs, and the lentiviral vectors were concentrated to a titer of $5 \times 10^{7} \mathrm{IFU} / \mathrm{ml}$. These findings demonstrated that FK506 is able to inhibit the rejection effect in a mouse-to-rat cardiac xenotransplantation model. FK506 treatment altered the expression levels of miR-146a and miR-155, indicating that they may have an important role in regulating the immune response to the rejection effect. miR-146a and miR-155 lentiviral vectors were successfully constructed for further experiments both in vitro and in vivo.
\end{abstract}

Correspondence to: Professor Weihua Fu or Professor Tong Liu, Department of General Surgery, Tianjin Medical University General Hospital, 154 Anshan Road, Tianjin 300052, P.R. China

E-mail: 1wdhw_33@sina.com

E-mail: baoaiww33@sina.com

Key words: xenotransplantation, FK506, hyperacute rejection, acute vascular rejection, miR-146a, miR-155, lentiviral vector

\section{Introduction}

Xenotransplantation is the transplantation of living cells, tissues or organs from one species to another. The use of animal organs in the field of transplantation offers a potentially limitless supply of organ sources for irreversible end-stage organ failure in humans $(1,2)$. Therefore, this is the main motivation behind xenotransplantation.

MicroRNA (miRNA), a class of non-coding RNA of 21-25 nucleotides, have been demonstrated to have important roles in various diseases. Functioning as regulatory molecules, miRNA are able to modulate gene expression by inhibiting the protein translation process and/or degrading the respective target messenger RNA (3).

Previous studies have shown that alterations in miRNA expression have been demonstrated to be associated with regulating the immune and inflammatory response, and as such they comprise a new class of immune regulatory factors. Previous studies by Taganov et al (4) and Nahid et al (5) have demonstrated that lipopolysaccharide (LPS) stimulation of the THP-1 human mononuclear cell line induced upregulation in three distinct types of miRNA, including miR-146a/b, miR-132 and miR-155. Further studies have suggested that the expression of miR-146 is induced by toll-like receptor (TLR) ligand, tumor necrosis factor (TNF)- $\alpha$, and interleukin (IL)-1 $\beta$, which indicates the involvement of $\mathrm{NF}-\kappa \mathrm{B}$ activation in the regulation of the immune response (4). More importantly, two important molecules, TNF receptor-associated factor 6 and IL-1 receptor-associated kinase 1 , have been shown to be the direct targets of miR-146 in the TLR/IL-1 $\beta$ pathway (6). Furthermore, O'Connell et al (7) have demonstrated that stimulation with interferon (IFN)- $\beta$, polyinosinic acid, IFN- $\gamma$ and LPS significantly upregulated miR-155 gene expression levels, and cytokine stimulation successfully induces alterations in miR-155 levels in the immune cells. Moreover, it has also been suggested that miR-155 is able to promote the translation of TNF- $\alpha$, indicating the underlying functional complexity of miR-155 in immune regulation (8).

The authors of the present study have previously demonstrated the expression pattern of miRNA in mouse-to-rat cardiac xenotransplantation rejection using microarray chip and quantitative polymerase chain reaction (qPCR) analysis. The results demonstrated an increase in the expression of miR-146a and miR-155 in cardiac xenotransplantation compared with allografts. Therefore, it is then plausible to consider miRNAs as therapeutic targets in transplant immune responses, particularly in xenotransplantation. 
The aim of the present study was to further elucidate the roles of miR-146a and miR-155 in xenotransplantation, and to investigate the expression levels of miR-146a and miR-155 in a cardiac xenograft model treated with FK506, which is a macrolide antibiotic with immunosuppressive properties (9). In addition, miR-146a and miR-155 lentiviral vectors were constructed in order to provide long-term and stable expression for subsequent research.

\section{Materials and methods}

Materials. A total of 24 inbred adult male BALB/c mice weighing 25-30 g, aged 70 \pm 5 days, were selected as donors, and 24 inbred adult male F344 rats weighing 250-300 g, aged $90 \pm 7$ days, were selected as recipients. All animals were purchased from the Animal Center of China Medical Sciences Academy Radiation Institute (Tianjin, China) and housed in temperature $\left(21-26^{\circ} \mathrm{C}\right)$ and humidity $(50-70 \%)$ controlled conditions with a $12 \mathrm{~h}$ light/dark cycle. Anti-mouse NF- $\kappa \mathrm{B}$ p65 (RelA) antibody was purchased from Cell Signaling Technology Inc., (Danvers, MA, USA). FK506 was purchased from Astellas Pharma Inc., (Tokyo, Japan). mirVana miRNA Isolation kit, miRNA reverse transcription kit and TaqMan MicroRNA Assays kit were purchased from Applied Biosystems (Thermo Fisher Scientific, Inc., (Waltham, MA, USA). The lentiviral vector system was purchased from System Biosciences, Inc., (Mumbai, India).

Establishment of a mouse-to-rat heterotopic cardiac xenograft model. A mouse-to-rat heterotopic cardiac xenograft model was established using the modified Heron cervical cuffing technique (10). For the surgery to be considered successful, the graft had to be bright red and beating strongly $12 \mathrm{~h}$ after the restoration of blood supply. Recipient rats were divided into the FK506 treatment group and the control group (sham injection), with each group containing 12 pairs of rats. The treatment group was treated with an intramuscular injection of FK506 (3 mg/kg/day) one day prior to the surgery until the first postoperative day. Six pairs of rats were randomly chosen from each group for perform subsequent experiments $24 \mathrm{~h}$ after transplantation, whereas the remaining rats were observed to determine the survival time of the grafts. Animals were sacrificed by cervical dislocation.

Hematoxylin and eosin (HE) staining for histopathological grading. Heart graft samples were collected $24 \mathrm{~h}$ after surgery and fixed in $10 \%$ buffered formaldehyde, embedded in paraffin, and sectioned at $5 \mu \mathrm{m}$ for HE staining. Histopathological changes in graft tissues were observed using optical microscopy. Grading was performed using the standardize guidelines of heart rejection published by ISHLT (11).

qPCR analysis. Expression levels of miR-146a and miR-155 were determined by qPCR using a TaqMan MicroRNA Assays kit. Reverse transcriptase reactions were incubated in a PTC-200 Thermal Cycler (MJ Research, Watertown, MA, USA) in a 96 -well plate for $30 \mathrm{~min}$ at $16^{\circ} \mathrm{C}$, followed by $30 \mathrm{~min}$ at $42^{\circ} \mathrm{C}, 5 \mathrm{~min}$ at $85^{\circ} \mathrm{C}$, and holding at $4^{\circ} \mathrm{C}$. qPCR was performed using a DNA Engine Opticon 2 system (MJ Research). The qPCR reaction mixture contained $1 \mu 1$ TaqMan
microRNA assay buffer (20X), $1.33 \mu 1$ reverse transcription product, $10 \mu \mathrm{l}$ TaqMan 2X Universal PCR Master Mix II and $7.67 \mu \mathrm{l}$ DEPC water. The following qPCR thermal cycling protocol was used: Denaturation $\left(95^{\circ} \mathrm{C}\right.$ for $\left.10 \mathrm{~min}\right)$, amplification and quantification $\left(40\right.$ cycles of $95^{\circ} \mathrm{C}$ for $15 \mathrm{sec}$ and $60^{\circ} \mathrm{C}$ for $60 \mathrm{sec}$ ), and melting curve analysis $\left(60-95^{\circ} \mathrm{C}\right.$, read every $0.2^{\circ} \mathrm{C}$, holding for $2 \mathrm{sec}$ ). U6 RNA (GenePharma, Shanghai, China) was used for normalization. Data were shown as fold change, according to the $2^{-\Delta \Delta \mathrm{Ca}}$ method (12), where $\Delta \Delta \mathrm{C}_{\mathrm{q}}=\left(\mathrm{C}_{\mathrm{qmiRNA}}-\mathrm{C}_{\mathrm{qU} \sigma}\right)_{\text {miRNA }}-\left(\mathrm{C}_{\mathrm{qmiRNA}}-\mathrm{C}_{\mathrm{qU}}\right)_{\text {ctrl }}$.

Western blot analysis. Radio immunoprecipitation assay lysis buffer (50 mM Tris-Cl, pH 7.4, $150 \mathrm{mM} \mathrm{NaCl,} 1 \%$ Triton $\mathrm{X}-100,0.1 \%$ SDS and $1 \%$ sodium deoxycholate) was used to lyse the graft tissue for $10 \%$ SDS-PAGE analysis. Separated proteins $(150 \mu \mathrm{g})$ were transferred to polyvinylidene fluoride membranes, washed in TBST buffer twice for $10 \mathrm{~min}$, and incubated with a primary antibody against NF- $\kappa \mathrm{B}$ p65 (RelA; 1:1,000; cat. no. 3034; Cell Signaling Technology, Inc.) for $12 \mathrm{~h}$ at $4^{\circ} \mathrm{C}$. Then, the membrane was washed with TBST buffer three times for 5 min and incubated with a goat anti-rabbit HRP-conjugated IgG secondary antibody (1:1,000; cat. no. ZB-2301; Zhongshan Golden Bridge Biotechnology Co., Ltd., Beijing, China) for $2 \mathrm{~h}$ at $23^{\circ} \mathrm{C}$. The membrane was stripped and reprobed with an antibody against GAPDH as a loading control. Proteins were detected with ChemiGenius 2 via GeneSnap software (Syngene, Frederick, MD, USA). Densitometry was performed on scanned images using Quantity One software 4.6.2 (Bio-Rad Laboratories, Inc., Hercules, CA, USA). Each experiment was performed in triplicate.

Construction of miR-146a and miR-155 lentiviral vectors. Pre-miR-146a and pre-miR-155 fragments were designed according to MiRBase and chemically synthesized with Pst I restriction site sequences for identification by Saier Biotechnology Co., Ltd. (Tianjin, China). Annealed pre-miR sequences were then ligated into the plasmid pCDH1-MCS1-EF1-copGFP. Recombinant plasmids were identified by PstI enzyme digestion and sequencing. Lentiviral vectors were packaged into 293T cells (Saier Biotechnology Co., Ltd.) and the viral titer was determined by plaque assay, as previously described (13), with serial dilutions of supernatants and observed under a fluorescence microscope.

Statistical analysis. Statistical analysis was performed using SPSS 16.0 statistical software (SPSS, Inc., Chicago, IL, USA). Measurement data were compared by Student's $t$-test, whereas ranked data were compared by Mann-Whitney U-test. Graft survival time was analyzed by Kaplan-Meier plot. $\mathrm{P}<0.05$ was considered to indicate a statistically significant difference.

\section{Results}

Survival time and histology of cardiac grafts. As shown in Fig. 1, the graft survival time in the FK506 treatment group $(41.67 \pm 1.63 \mathrm{~h})$ was significantly increased when compared with the control group $(32.17 \pm 1.47 \mathrm{~h} ; \mathrm{P}<0.05)$. Cardiac grafts in the treatment group were bright red in color, soft, and beating strongly, without surrounding adhesion or blood clots 
in the lumen at $24 \mathrm{~h}$ post-operation (Fig. 2A). In comparison, at the same time-point, grafts in the control group were darker red in color, congestive and beating weakly, with considerable surrounding adhesion and blood clots in the lumen (Fig. 2B). Heart grafts in the syngeneic group exhibited no myocardial fiber or vascular damage and no evidence of mononuclear inflammation (Fig. 3A and B). Mild distortion of the normal tissue architecture was observed in the FK506 treatment group; however, there was no evidence of myocardial damage, interstitial hemorrhage or vasculitis (Fig. 3C and D). In the control group, microscopic assessment revealed infiltration of lymphocytes and macrophages, edema, interstitial hemorrhage and vasculitis (Fig. 3E and F). Histopathological grading results are shown in Table I.

Expression levels of miR-146a and miR-155 in cardiac graft tissue. As shown in Table II, qPCR analysis demonstrated a significant increase of 3.1-fold in miR-146a expression levels in the treatment group compared with the control group $(\mathrm{P}<0.05)$. Conversely, there was a significant decrease in miR-155 expression by 0.3 -fold $(\mathrm{P}<0.05$; Table III).

Expression of RelA protein in graft tissue. As shown in Table IV and Fig. 4, western blot analysis demonstrated a significant decrease in the protein expression levels of RelA in the graft tissue of the treatment group, as compared with the control group $(\mathrm{P}<0.05)$.

Restriction endonuclease analysis and DNA sequencing of plasmids. Restriction endonuclease analysis of pCDH1-MCS1-EF1-copGFP/146a and pCDH1-MCS1-EF1copGFP/155 was performed using PstI digestion as described. The $1150 \mathrm{kbp}$ fragment is shown in lanes 1-6 of Fig. 5A and lanes $1-5$ and 7 in Fig. 5B, as expected. DNA sequencing results for both pCDH1-MCS1-EF1-copGFP/146a and pCDH1-MCS1-EF1-copGFP/155 indicated that the sequences of the recombinant plasmids were correct and there were no mutations (Fig. 6A and B, respectively).

Titer of miR-146a and miR-155 lentiviral vectors. Lentiviral vectors were concentrated to reach a titer of $5 \times 10^{7} \mathrm{IFU} / \mathrm{ml}$. As shown in Fig. 7, 293T cells expressed green fluorescence following transfection with lentiviral vectors demonstrating successful infection.

\section{Discussion}

Significant progress has been made in studying the role of miRNA in regulating the nervous and hematopoietic system, as well as in the immune response in diseases such as cancer; however, the role of miRNA in xenotransplantation remains poorly understood (14). In the present study, FK506, which is a macrolide antibiotic with immunosuppressive properties, was used to further elucidate the roles of miR-146a and miR-155 in xenotransplantation. The present findings showed that the survival time of cardiac grafts was significantly increased in the FK506 treatment group by $10 \mathrm{~h}$, as compared with the control group. The overall condition of the grafts in the treatment group was demonstrated to be better than that of the control group from gross and microscopic appearance

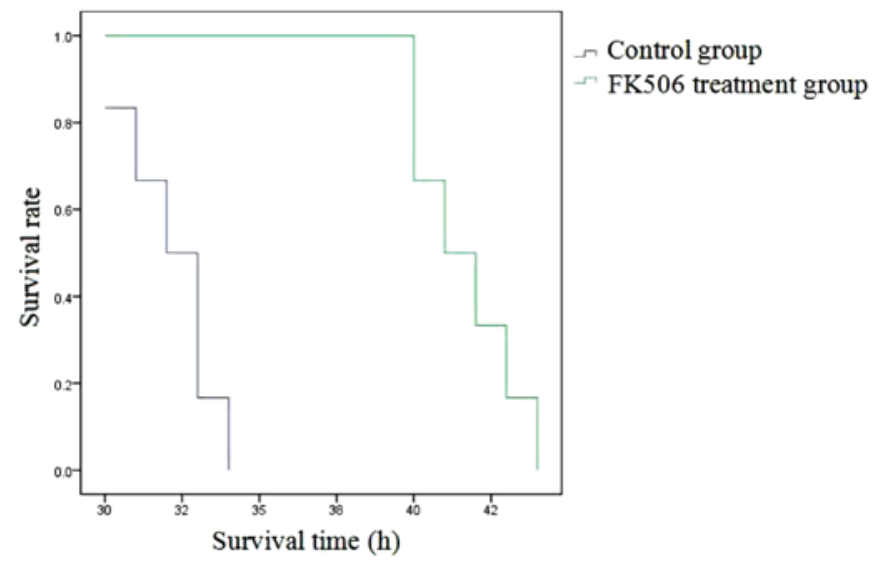

Figure 1. Survival time of cardiac grafts. The survival time of the cardiac grafts in both the FK506 treatment group and the control group was analyzed by Kaplan-Meier plot analysis.

following HE staining. A similar result was observed with histopathological grading. Therefore, these findings indicated that FK506 is able to inhibit the rejection effect in a mouse-to-rat cardiac xenotransplantation model. This result is consistent with a previous report that FK506 can prolong the survival time of grafts in mouse to rat cardiac xenotransplantation in combination with other therapeutics (15). FK506 has also been shown to achieve similar results in other types of xenotransplantation models (16).

The role of miRNA has recently been recognized in the immune system; however, there are few reports on their role in organ transplantation to date. Sui et al (17) identified 20 miRNA that were expressed at varying levels during acute rejection after renal transplantation. In another study, 62 miRNA were found to be upregulated in the small bowel during acute cellular rejection, and 35 were downregulated (18). Numerous studies have suggested the potential involvement of miRNA in the pathogenesis of allograft rejection $(19,20)$; however, no studies have been reported in the case of xenotransplantation. Previous research by the authors of the present study demonstrated a significant increase in the expression levels of miR-146a and miR-155 in mouse-to-rat cardiac xenotransplantation, as compared with allografts by microarray chip and qPCR. In the present study, the FK506 treatment group exhibited a significant increase in miR-146a expression levels when compared with the control group. Conversely, there was a significant decrease in miR-155 expression levels observed in the treatment group. Following treatment with FK506, the differing intragraft expression levels of miR-146a and miR-155 indicated that they may potentially have an important role in regulating the immune response for xenograft rejection.

By means of promoter analysis, miR-146a was previously found to be an NF-kB-dependent gene (4). In addition, Bhaumik et al (21) suggested that miR-146a/b is expressed in response to increasing inflammatory cytokine levels as part of a negative feedback loop. In the present study, inhibition of the rejection effect by FK506 was observed in the xenografts, whereas upregulation of miR-146a and downregulation of RelA, which is a family member of NF- $\kappa \mathrm{B}$, were also observed. Therefore, we hypothesize that miR-146 may have a role in controlling the xenograft rejection effect through a 
Table I. Histopathological grading of grafts in two groups $(n=6)$.

\begin{tabular}{lcccccr}
\hline & \multicolumn{5}{c}{ Histopathological grade } & \\
\cline { 2 - 5 } Group & 0 & 1 & 2 & 3 & $\mathrm{Z}$ & P-value \\
\hline Treatment & 1 & 5 & 0 & 0 & 3.052 & 0.002 \\
Control & 0 & 0 & 2 & 4 & & \\
\hline
\end{tabular}

Mann-Whitney U test; compared with the control group.

A

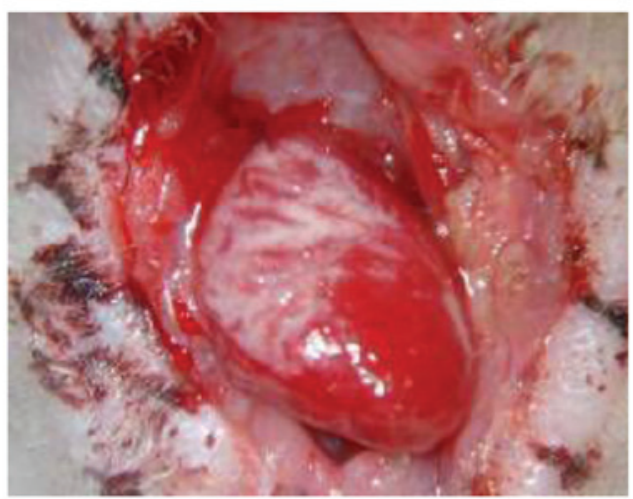

B

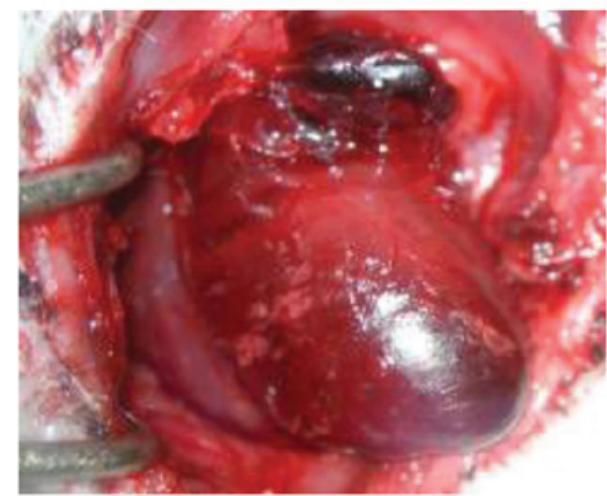

Figure 2. Gross appearance of cardiac grafts $24 \mathrm{~h}$ post-surgery. Gross appearance of the cardiac grafts in the (A) FK506 treatment and (B) control groups.

A

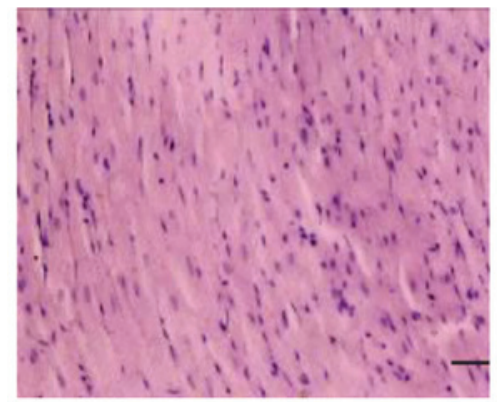

$\mathbf{D}$

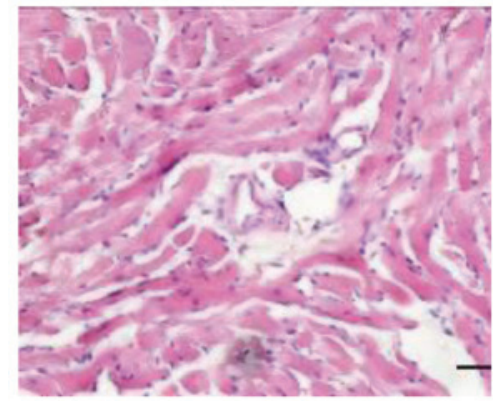

B

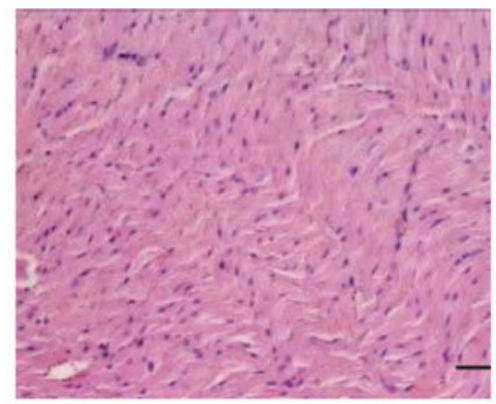

E

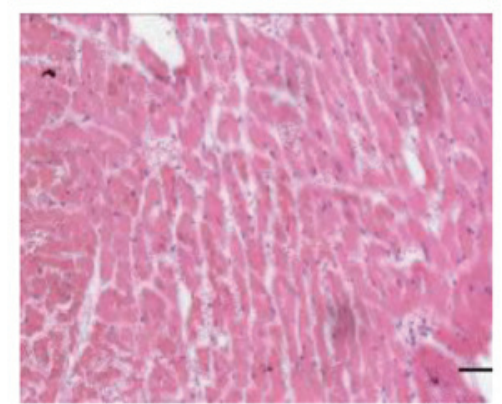

C
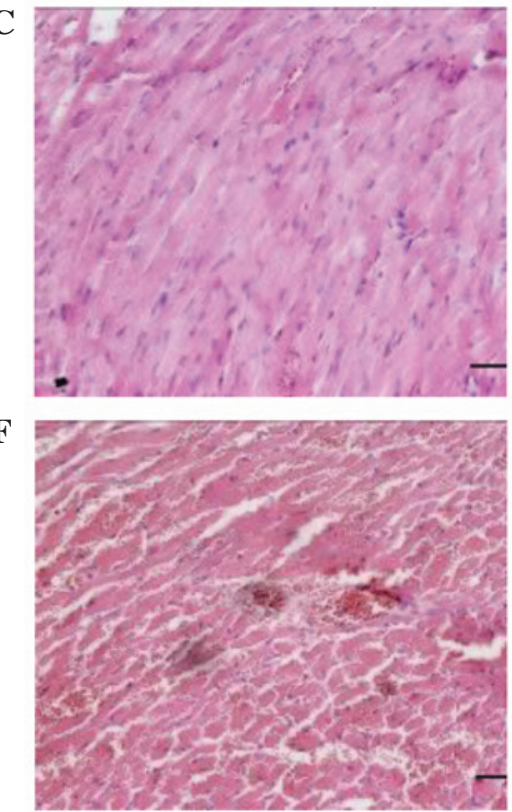

Figure 3. Histology of BALB/c mouse heart xenografts in F344 rat recipients in different groups. (A) Heart grafts were harvested at $24 \mathrm{~h}$ after BALB/c-to-BALB/c mouse isografting; normal histology was detected. (B) Heart grafts were harvested at $40 \mathrm{~h}$ after BALB/c-to-BALB/c mouse isografting. There was no evidence of rejection. (C) Heart grafts were harvested at $24 \mathrm{~h}$ after BALB/c mouse-to-F344 rat xenotransplantation treated with FK506. Mild distortion of the normal tissue architecture was observed. (D) Heart grafts were harvested at $40 \mathrm{~h}$ after BALB/c mouse-to-F344 rat xenotransplantation treated with FK506. There was no evidence of myocardial damage, interstitial hemorrhage or vasculitis. (E) Heart grafts were harvested at $24 \mathrm{~h}$ after BALB/c mouse-to-F344 rat xenotransplantation. Heart xenografts exhibited mild to moderate vasculitis; however, no thrombosis was detected. (F) Heart grafts were harvested at $40 \mathrm{~h}$ after BALB/c mouse-to-F344 rat xenotransplantation. Heart xenografts were rejected with severe interstitial hemorrhage, vascular structures collapse, and intravascular thrombosis. (magnification, $\mathrm{x} 200$; scale bar, $50 \mu \mathrm{m}$ ).

negative feedback regulation loop involving the downregulation of NF-kB, which is the core of acute vascular rejection.
Stahl et al (22) found that miR-155 inhibition in conventional $\mathrm{CD}^{+}$Th cells strengthened nTreg cell-mediated 
Table II. Expression of miR-146a $(\bar{x} \pm s)$.

\begin{tabular}{lccccr}
\hline Group & $\Delta \mathrm{Ct}$ & $2^{-\Delta \mathrm{Ct}}\left(\mathrm{x} 10^{-4}\right)$ & $\Delta \Delta \mathrm{Ct}$ & $2^{-\Delta \Delta \mathrm{Ct}}$ & $t$ \\
\hline Treatment & $4.877 \pm 0.102$ & $341.330 \pm 23.813$ & -1.640 & 3.117 & 21.785 \\
Control & $6.517 \pm 0.140$ & $109.670 \pm 10.558$ & 0 & 1 & $<0.001$ \\
\hline
\end{tabular}

Student's $t$-test; compared with the control group.

Table III. Expression of miR-155 ( $\bar{x} \pm s)$.

\begin{tabular}{lrrrrr}
\hline Group & $\Delta \mathrm{Cq}$ & $2^{-\Delta \mathrm{Cq}}\left(\mathrm{x} 10^{-4}\right)$ & $\Delta \Delta \mathrm{Cq}$ & $2^{-\Delta \Delta \mathrm{Cq}}$ & $t$ \\
\hline Treatment & $11.428 \pm 0.084$ & $3.633 \pm 0.213$ & 1.847 & 0.278 & 12.013 \\
Control & $9.581 \pm 0.214$ & $13.333 \pm 1.966$ & 0 & 1 & $<0.001$ \\
\hline
\end{tabular}

Student's $t$-test; compared with the control group.

Table IV. Relative expression levels of RelA.

\begin{tabular}{lccc}
\hline Group & RelA & $t$ & P-value \\
\hline Treatment & $0.572 \pm 0.007$ & 174.430 & $<0.001$ \\
Control & $1.581 \pm 0.120$ & & \\
\hline
\end{tabular}

Student's t-test; compared with the control group.

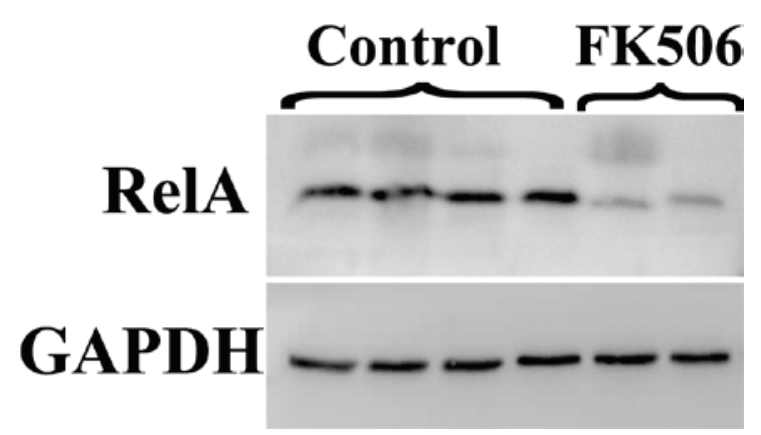

Figure 4. Comparison of the protein expression levels of RelA, as detected by western blot analysis. Protein expression analysis for RelA in graft tissue treated with FK506 or controls.

suppression. Furthermore, deficiency in miR-155 has been shown to lead to impaired primary and secondary immune responses and reduced IgG1 secretion (23). In the present study, following suppression of rejection by FK506, expression levels of miR-155 were also observed to decrease in accordance with previous studies $(22,23)$.

At present, lentiviral-mediated miRNA targeted therapy has rarely been reported in xenotransplantation; however some progress has been made in other fields. Li et al (24) constructed a miR-101 over-expressing vector that suppressed the metastasis of chorioepithelioma in vitro. Furthermore, Ma et al (25) suggested that miR-10b is highly expressed in metastatic breast cancer cells and positively regulates cell migration and invasion. Overexpression of miR-10b in

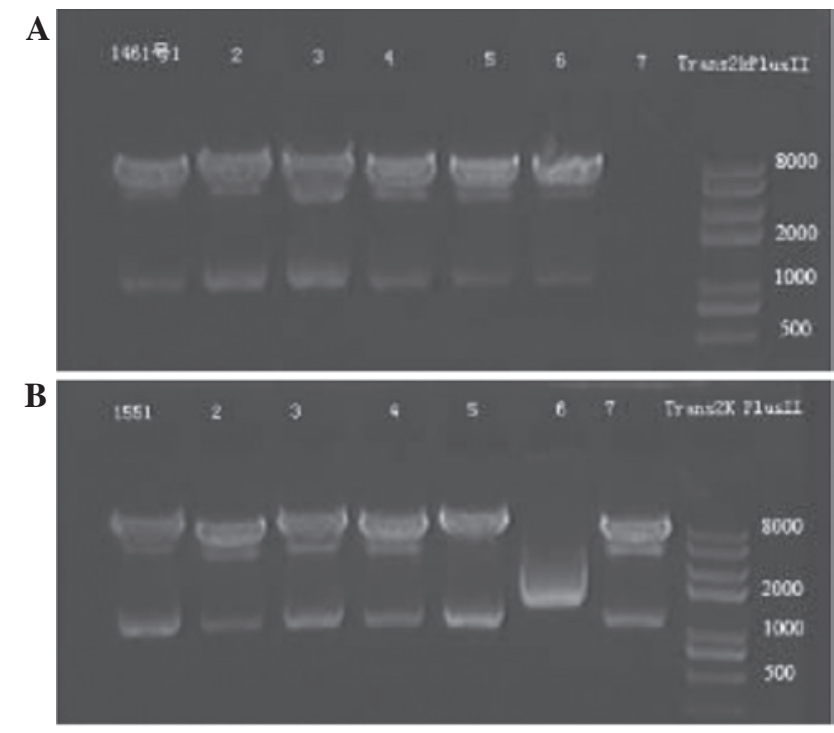

Figure 5. Identification of recombinant expression plasmids by restriction endonuclease digestion analysis. Lane 1-7: Recombinant plasmids digested with PstI. (A) 1\% agarose gel electropherogram of restriction endonuclease analysis for pCDH1-MCS1-EF1-copGFP/146a; (B) $1 \%$ agarose gel electropherogram of restriction endonuclease analysis for pCDH1-MCS1-EF1-copGFP/155.

non-metastatic breast tumors also initiated robust invasion and metastasis.

The results of the present study demonstrated a difference in the expression levels of miR-146a and miR-155 in xenograft rejection. Firstly, this indicates that miRNA have the potential to be excellent biomarkers for xenograft status. Secondly, given the critical role of miRNA in immune cell homeostasis, there is a distinct possibility that RNA interference strategies may be developed to modulate the transplant immune repertory. As the manipulation of one miRNA may have an impact on multiple mRNA, and since one mRNA may be regulated by multiple miRNAs, miRNA may provide an exciting framework for novel therapeutic interventions in xenotransplantation. 

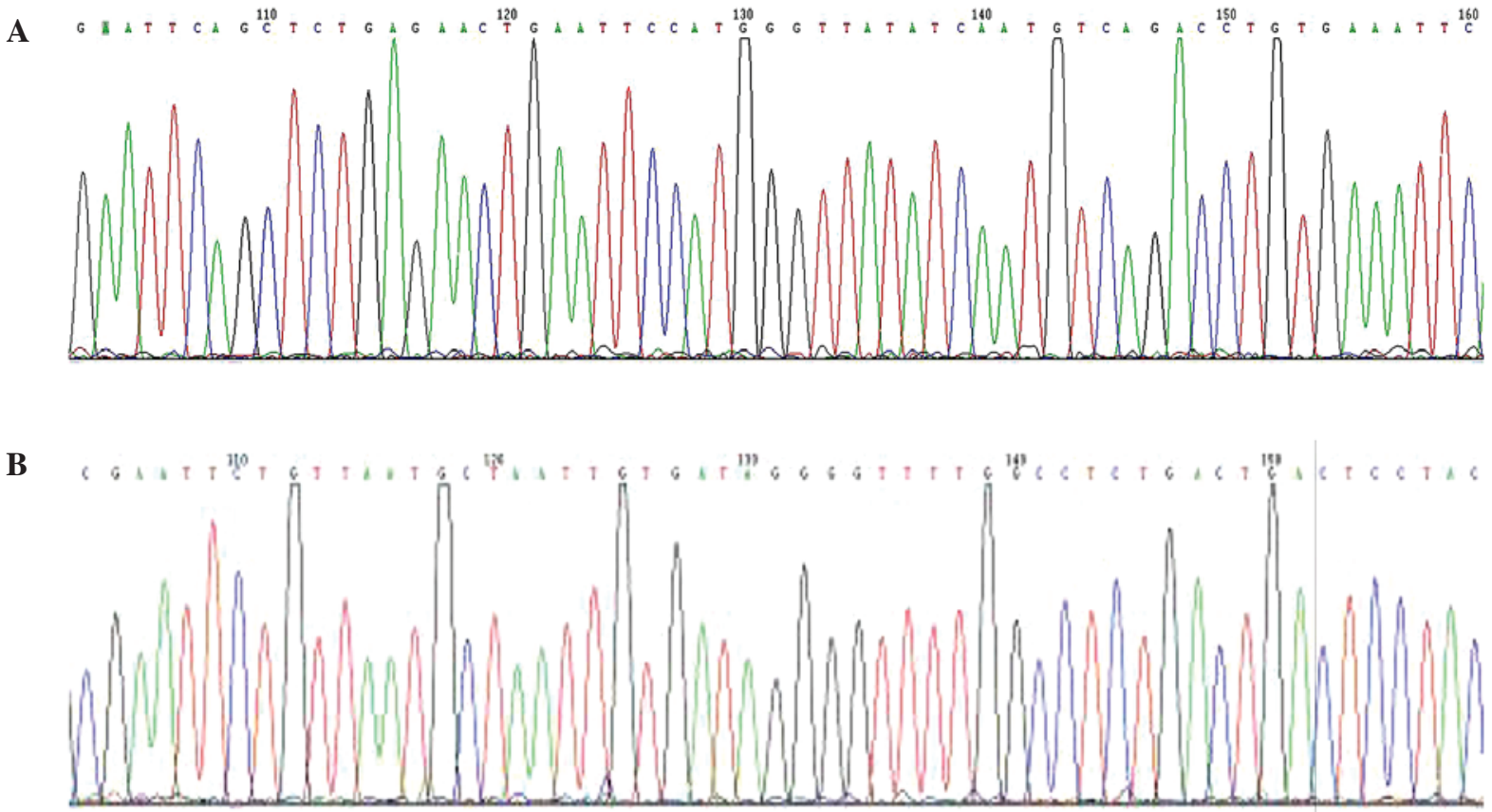

Figure 6. DNA sequencing for pCDH1-MCS1-EF1-copGFP/146a and pCDH1-MCS1-EF1-copGFP/155. (A) miR-146a and (B) miR-155 were confirmed by automated sequencing.

A

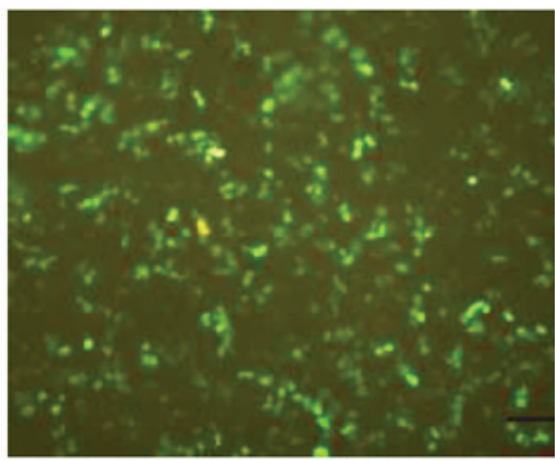

B

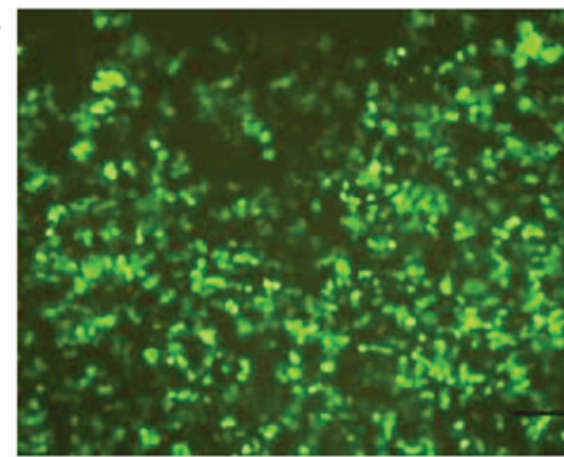

Figure 7. Fluorescent expression in $293 \mathrm{~T}$ cells infected by miR-146a and miR-155 lentiviral vector. $293 \mathrm{~T}$ cells were transfected with lentiviral vectors (A) miR-146a and (B) miR-155. Images were captured by a fluorescent microscope at $24 \mathrm{~h}$ post transduction using the same exposure time (magnification, $\mathrm{x} 200$; scale bar, $50 \mu \mathrm{m})$.

\section{Acknowledgements}

This study was supported by the Tianjin Public Health Bureau of Science and Technology Fund (grant no. 2014KZ123).

\section{References}

1. Cooper DKC and Lanza RP (eds): Xeno: The promise of transplanting animal organs into humans. Oxford University Press, New York pp1-274, 2000.

2. Ekser B, Ezzelarab M, Hara H, van der Windt DJ, Wijkstrom M, Bottino R, Trucco M and Cooper DK: Clinical xenotransplantation: The next great medical revolution? Lancet 379: 672-683, 2012.

3. Bartel DP: MicroRNAs: Target recognition and regulatory functions. Cell 136: 215-233, 2009.

4. Taganov KD, Boldin MP, Chang KJ and Baltimore D: NF-kappaB-dependent induction of microRNA miR-146, an inhibitor targeted to signaling proteins of innate immune responses. Proc Natl Acad Sci USA 103: 12481-12486, 2006.
5. Nahid MA, Pauley KM, Satoh M and Chan EK: MiR-146a is critical for endotoxin-induced tolerance: Implication in innate immunity. J Biol Chem 284: 34590-34599, 2009.

6. Hou J, Wang P, Lin L, Liu X, Ma F, An H, Wang Z and Cao X: MicroRNA-146a feedback inhibits RIG-I-dependent type I IFN production in macrophages by targeting TRAF6, IRAK1, and IRAK2. J Immunol 183: 2150-2158, 2009.

7. O'Connell RM, Taganov KD, Boldin MP, Cheng G and Baltimore D: MicroRNA-155 is induced during the macrophage inflammatory response. Proc Natl Acad Sci USA 104: 1604-1609, 2007.

8. Ruggiero T, Trabucchi M, De-Santa F, Zupo S, Harfe BD, McManus MT, Rosenfeld MG, Briata P and Gherzi R: LPS induces KH-type splicing regulatory protein-dependent processing of microRNA-155 precursors in macrophages. FASEB J 23: 2898-2908, 2009.

9. Jones-Hughes T, Snowsill T, Haasova M, Coelho H, Crathorne L, Cooper C, Mujica-Mota R and Peters J: Immunosuppressive therapy for kidney transplantation in adults: A systematic review and economic model. Health Technol Assess 20: 1-594, 2016.

10. Heron I: A technique for accessory cervical heart transplantation in rabbits and rats. Acta Pathol Microbiol Scand A 79: 366-372, 1971 
11. Stewart S, Winters GL, Fishbein MC, Tazelaar HD, Kobashigawa J, Abrams J, Andersen CB, Angelini A, Berry GJ, Burke MM, et al: Revision of the 1990 working formulation for the standardization of nomenclature in the diagnosis of heart rejection. J Heart Lung Transplant 24: 1710-1720, 2005.

12. Livak KJ and Schmittgen TD: Analysis of relative gene expression data using real-time quantitative PCR and the $2-\Delta \Delta \mathrm{Ct}$ method. Methods 25: 402-408, 2001.

13. Jiang QL, Wang JM, Jiang S, Wen LM and Zhou H: Large-scale real-time titration of green-fluorescence-protein-marked recombinant retrovirus: comparison with standard titration method. J First Mil Med Univ 23: 1101-1103, 2003.

14. Bartel DP: MicroRNAs: Genomics, biogenesis, mechanism, and function. Cell 116: 281-297, 2004.

15. Qi F, Zhu LW, He XH, et al: Research on function of combined drugs of immune rejection in mouse to rat cardiac xenotransplantation. Shangdong Med J 50: 12-14, 2010.

16. Zou XM, Li XL, Li F, et al: Effect of immunosuppressant FK506 on syrian hamster to rat small bowel xenotransplantation. Zhong Hua Wei Chang Wai Ke Za Zhi 6: 251-254, 2003.

17. Sui WG, Dai Y,Huang Y,Lan H, Yan Q and Huang H: Microarray analysis of MicroRNA expression in acute rejection after renal transplantation. Transpl Immunol 19: 81-85, 2008.

18. Sotolongo B, Asaoka T, Island E, Carreno M, Delacruz V, Cova D, Russo C, Tryphonopoulos P, Moon J, Weppler D, et al: Gene expression profiling of MicroRNAs in small-bowel transplantation paraffin-embedded mucosal biopsy tissue. Transplant Proc 42: 62-65, 2010
19. Jelencsics K and Oberbauer R: microRNA and kidney transplantation. Adv Exp Med Biol 888: 271-290, 2015.

20. Vitalone MJ, Wei L, Fujiki M, Lau AH, Littau E, Esquivel C, Martinez OM and Krams SM: Liver microRNA profile of induced allograft tolerance. Transplantation 100: 781-790, 2016.

21. Bhaumik D, Scott GK, Schokrpur S, Patil CK, Orjalo AV, Rodier F, Lithgow GJ and Campisi J: MicroRNA miR-146a/b negatively modulate the senescence-associated inflammatory mediators IL-6 and IL-8. Aging (Albany NY) 1: 402-411, 2009.

22. Stahl HF, Fauti T, Ullch N, Bopp T, Kubach J, Rust W, Labhart P, Alexiadis V, Becker C, Hafner M, et al: MiRNA-155 inhibition sensitizes CD4+ Th cells for TREG mediated suppression. PLoS One 4: e7158, 2009.

23. Vigorito E, Perks KL and Abreu-Goodger C, Bunting S, Xiang Z, Kohlhaas S, Das PP, Miska EA, Rodriguez A, Bradley A, et al: MicroRNA-155 regulates the generation of immunoglobulin class-switched plasma cells. Immunity 27: 847-859, 2007.

24. Li M, Liu ZX, Liu T, Cheng W, Gao Y and Wang H: The built eukaryotic expression vector of microRNA-101 and the expression in the human placenta carcinoma cells. Zhong Guo Lin Chuang Yi Xue 17: 627-630, 2010.

25. Ma L, Teruya-Feldstein J and Weinberg RA: Tumor invasion and metastasis initiated by microRNA-10b in breast cancer. Nature 449: 682-688, 2007. 